\title{
El papel de la revista Arte Comercial en la conceptualización de las Relaciones Públicas en España
}

\author{
Arte Comercial aldizkariak Espainian \\ Harreman Publikoak kontzeptualizatzeko \\ prozesuan izan duen zeregina
}

\section{The role of Arte Comercial in the conceptualization of Public Relations in Spain}

\author{
Jesús Reina Estévez
}

\section{zer}

Vol. 21 - Núm. 40

ISSN: $1137-1102$

e-ISSN: $1989-631 \mathrm{X}$

DOI: $10.1387 /$ zer. 15513

pp. $141-158$

2016

Recibido el 1 de noviembre de 2015, aceptado el 3 de febrero de 2016

\section{Resumen}

El presente estudio tiene por objetivo localizar referencias a la ciencia de las relaciones públicas en la revista técnica de publicidad y organización, Arte Comercial (1946-1952). Partiendo de la técnica de la revisión bibliográfica, se identifican los números de interés, así como los artículos y autores que abordan el tema de las relaciones públicas dentro de la publicación. Los resultados se presentan debidamente conceptualizados y contextualizados, pues son prueba fehaciente de que la disciplina empezó a ser conocida en España durante los años cuarenta, antes del inicio oficial de la profesión a principios de la década de los sesenta.

Palabras clave: Relaciones públicas, relaciones generales, buenas relaciones, Arte Comercial, GARÚ.

\section{Laburpena}

Ikerketa honen helburua da publizitateari eta antolakuntzari buruzko Arte Comercial (19461952) aldizkari teknikoan harreman publikoen zientziari egin zaizkion erreferentziak kokatzea. Berrikusketa bibliografikoaren teknika erabiliz, interesgarriak izan zitezkeen zenbakiak identifikatu dira, baita aldizkarian harreman publikoei buruz hitz egiten duten artikuluak eta autoreak ere. Emaitzak behar bezala kontzeptualizatu dira, eta dagokien testuinguruan jarri;

1 Universidad de Málaga, Jeres@uma.es 
izan ere, argi erakusten dute harreman publikoen diziplina berrogeiko hamarkadan egin zela ezagun Espainian, lanbidea hirurogeiko hamarkadaren hasieran ofizialki agertu baino lehen.

Gako-hitzak: Harreman publikoak, harreman orokorrak, harreman onak, Arte Comercial, GARÚ.

\section{Abstract}

This study try to find references to the science of public relations in the advertising and organization magazine, Arte Comercial (1946-1952). It's based on the technique of the literature review, they are identified the numbers of interest, as well articles and authors that address the issue of public relations. The results are presented properly conceptualized and contextualized, they are proof that the discipline began to be known in Spain during the forties, before the official start of the profession in the early sixties.

Keywords: Public relations, general relations, good relations, Arte Comercial, GARÚ. 


\section{Introducción}

Pasada la Guerra Civil, España entró en un periodo de aislamiento internacional, miseria y autarquía, donde el poder adquisitivo de sus ciudadanos era casi nulo, la calidad de los productos dejaba mucho que desear, y abundaban los sucedáneos (Eguizábal, 1998: 473).

Los profesionales de la comunicación comercial se movían dentro del ámbito publicitario, y su situación era también precaria: se percibe una falta de tecnificación y formación, desprestigio social, escasa remuneración -hasta el punto de convertir a la publicidad en un segundo empleo-, y el nulo control de la actividad profesional (Pérez Ruiz, 2001: 220).

La situación de las agencias de publicidad no era mejor. Las pocas agencias importantes andaban "literalmente en pañales", ya que adolecían de una falta de formación, medios y estructuras. Para ser comprendidos por los clientes, las agencias debían valerse de un lenguaje extremadamente sencillo y actuar como todoterrenos. Sus servicios comprendían todos los aspectos relacionados con las campañas de comunicación, incluyendo las acciones de promoción, la publicidad directa y las relaciones públicas (Fontcuberta, 1998: 14-18). También se percibía un estancamiento en la forma de proceder de las agencias, debido al aislamiento internacional y a la falta de ideas nuevas y prácticas renovadas procedentes de otros mercados publicitarios, como el europeo o norteamericano (Checa, 2007: 149). Se hacía lo que se podía con lo que se sabía.

Durante el quinquenio de 1947-1952, se produce una toma de conciencia del nivel de decaimiento profesional. Con el deseo de mejorar la organización y el nivel de los agentes publicitarios, se empieza a debatir sobre la necesidad de fundar organismos e instituciones profesionales y de aumentar la calidad de la actividad técnica publicitaria (Pérez Ruiz, 2001: 191). Algunos expertos optan por elevar el nivel académico de la comunicación en España, centrándose en la difusión de conocimientos teóricos y prácticos a través de publicaciones especializadas, con el objetivo de actualizar y mantener informados a los trabajadores en activo.

Este fue el caso de la revista Arte Comercial (1946-1952), editada por el publicitario Emeterio Ruiz Melendreras, y enfocada hacia la organización comercial y la publicidad. Sus artículos tratan aspectos genéricos de la actividad publicitaria, como "el escaparatismo, cartel y arte publicitario, la radio publicitaria, la publicidad bancaria, la publicidad colectiva, las marcas, el color en la publicidad, los problemas de venta, el poder del envase...” (Eguizábal, 2003). Rápidamente, la publicación se convierte en un punto de encuentro para tratar nuevas ideas y debatir sobre las técnicas más desconocidas y novedosas.

En el ámbito de las relaciones públicas, la revista Arte Comercial tiene un papel destacado, ya que es la primera publicación española de la que tenemos constancia que aborda por primera vez la disciplina de las relaciones públicas a través de su conceptualización teórica y algunas menciones menores. Estas referencias se producen de la mano de varios profesionales patrios de la publicidad, como Jorge Garriga, Pedro Prat Gaballí y Francisco García Ruescas, desde casi el comienzo de su singladura. Pasados estos años de formación y aprendizaje, serán las agencias de publicidad patrias las encargadas de llevar a cabo las primeras campañas de 
relaciones públicas en España, dando lugar al inicio oficial de la profesión a principio de los años sesenta.

\section{Estado de la cuestión}

La tendencia académica tradicional sitúa el nacimiento oficial de las relaciones públicas en España en la utilización consciente de la nomenclatura por parte de los profesionales en sus campañas de comunicación, a partir de los años sesenta, precedida por un pequeño grupo de precedentes en forma de "campañas de prestigio" (Almansa, 2011; Castillo, 2009; Fontcuberta, 1998; López Castro, 2005; Noguero i Grau, 1995; Rodríguez Salcedo, 2010; Xifra, 2010). Frente a esta corriente reinante, se encuentran aquellos teóricos que no conciben unas verdaderas relaciones públicas sin una serie de garantías y requisitos, como la libertad de expresión u organización. Por tanto, consideran que el nacimiento de la disciplina no se producirá en España hasta el advenimiento de la Democracia (Arceo, 1995a, 1995b, 2004a, 2004b, 2006).

En la última década, se ha venido reclamando una reformulación del paradigma histórico, ya que algunos historiadores de la comunicación consideran que el origen de la disciplina se podría rastrear hasta finales del siglo XIX, en forma de actividades y manifestaciones aisladas de relaciones públicas, encuadradas en una larga etapa de antecedentes (Armendáriz, 2012; Montero, Rodríguez y Verdera, 2010; Reina, 2015; Reina y González, 2014a; Reina, 2014b; Rodríguez Salcedo, 2007).

En cuanto a los primeros autores que escriben sobre la teoría de las relaciones públicas en España, tenemos constancia de algunos manuales de publicidad de la década de los cincuenta que dedican uno o parte de sus capítulos a conceptualizar la disciplina, como la obra de Pedro Prat Gaballí, "Publicidad Combativa" (1953) o "Mass Comunications" (1957), de Juan Beneyto (Reina y González, 2014b). Por su parte, el primer libro sobre relaciones públicas publicado en España fue "Las relaciones públicas en el ámbito local" en 1958, firmado por Marqués Carbó y Marqués Canós, sobre la situación de la disciplina en EEUU (Almansa, 2011: 37).

La revista Arte Comercial surge a mediados de los años cuarenta. A pesar de su antigüedad, no existe ningún estudio pormenorizado sobre la misma (Ríos, 2004: 155). Su análisis se ha venido realizando desde el ámbito publicitario (Eguizábal, 2003; Pérez Ruiz, 2001) y del diseño gráfico (Ríos, 2004), como fuente documental más que proveedora de contenido teórico, por lo que se ha pasado por alto su potencial para los historiadores de las relaciones públicas en España.

\section{Metodología}

Este estudio se vale de la revisión bibliográfica para inferir sus resultados, y se encuadra en el grupo de estudios de tipo formulativo o exploratorio, ya que su finalidad es encontrar ideas y aspectos novedosos para posteriores investigaciones más detalladas (Selltiz, Clawrence, y Cook, 1980: 133). El principal objetivo de esta investigación es rastrear los primeros escritos académicos sobre la disciplina de las relaciones públicas que se difunden en España, circunscritos al ámbito de publicación de la revista especializada, Arte Comercial: Revista Técnica de Publicidad y Organización. 
La elección de este universo de estudio no es fortuita, ya que la revista Arte Comercial tiene un importante papel en la historia de la comunicación en nuestro país por varios motivos: en primer lugar, por el difícil momento de su publicación, desde Abril de 1946 hasta mediados de 1952. Durante estos años, el panorama comunicativo español es precario, ya que trata de recuperarse y alcanzar el nivel de antes de la Guerra Civil, pero también destaca por ser un momento de cambio, donde se empiezan a importar ideas y nuevas técnicas procedentes del ámbito internacional. La revista Arte Comercial viene a dar fe de esa situación. En segundo lugar, por el espíritu de innovación del que hace gala, ya que la publicación no se limita a tratar temas exclusivamente publicitarios, sino que se adentra en otros terrenos considerados nuevos o intermedios, como el marketing, la formación del personal o el arte del cartel. En tercer lugar, se trata de una colección pequeña y cerrada, que cuenta con 41 números en su haber, casi todos disponibles para su consulta en abierto. Por último, la revista Arte Comercial es una publicación bastante desconocida en el ámbito académico de la comunicación española, algo que se percibe en la falta de investigaciones y estudios monográficos.

Para la elaboración de la metodología nos basamos en un modelo de cuatro etapas (Gómez-Luna et al., 2014), que pasa por definir el problema, buscar la información, organizar esta información y analizarla.

En nuestro caso, las etapas de búsqueda y organización de la información son coincidentes, ya que nuestro objetivo es encontrar datos sobre las relaciones públicas en una publicación periódica concreta. La definición del problema implica que existe una necesidad de investigación; esta necesidad se materializa en el imperativo de encontrar pruebas documentales de que las relaciones públicas eran conocidas por los académicos de la profesión en España antes de la década de los años cincuenta, cuando se llevan a cabo las primeras campañas de relaciones públicas en nuestro país. Tradicionalmente, se ha considerado que las primeras actuaciones en el terreno de relaciones públicas las puso en marcha la agencia barcelonesa Danis, cuando ideó unas "campañas sociales" para diversas marcas comerciales, con el objeto de dar una imagen más humana y cercana de las firmas (Fontcuberta, 1998: 176-187). Por tanto, resulta lógico, y hasta necesario, suponer que antes de la materialización de estas campañas, existía en nuestro país una corriente favorable y el suficiente nivel de conocimiento teórico sobre las relaciones públicas para la organización y ejecución de algunas actividades. Este estudio se propone arrojar algunos resultados a favor de esa tesis.

La búsqueda y organización de la información supuso la localización y descarga de los números de la revista Arte Comercial ${ }^{2}$. El estado de conservación de estos documentos es impresionante, y su accesibilidad es fácil y gratuita. No obstante, la colección está incompleta, ya que no se encuentra el último número de la publicación, el número 41. A efectos prácticos, esta eventualidad no afecta a la búsqueda y localización de resultados, pero si supone un contratiempo, ya que impide saber a ciencia cierta de qué manera y cuáles fueron los argumentos esgrimidos por la publicación -si es que los hubo- para cerrar la revista.

Por último, el análisis de la información conlleva la localización de las unidades de registro de valor para el estudio. En nuestro caso, aquellos números donde se

2 http://www.memoriademadrid.es/ 
alude, de alguna manera, a las relaciones públicas. Esta fase implica la lectura pormenorizada y detallada de los diferentes artículos relacionados con nuestro ámbito de interés. Para hallar estos artículos fue requisito indispensable analizar el índice de cada número, recabando aquellos textos que aludieran a una serie de palabras clave, como las fórmulas y nomenclaturas que de una manera u otra se han venido usando para referirse a las relaciones públicas ${ }^{3}$, o autores de interés históricamente relacionados con la disciplina. Nunca está de más acudir al sentido común.

En este punto nos encontramos con una dificultad añadida a la hora de encontrar palabras clave, todo un hándicap ya de la profesión de las relaciones públicas: la variedad terminológica con que se alude o se traduce el término de las relaciones públicas en los primeros años de implantación en nuestro país. Al tratarse de un término anglosajón importado, las public relations van a ser traducidas de las más diversas formas, ya que cada autor sugiere su personal fórmula: buenas relaciones, relaciones generales, relaciones sociales, relaciones con los públicos...

Una vez encontrados, leídos y comprendidos los artículos de interés, es posible exponer los resultados. Para ello fue preciso realizar una revisión exhaustivo-descriptiva (Guirao-Goris, Olmedo y Ferrer, 2008: 6), con carácter retroactivo. Ya que el objeto de este estudio no se limita sólo a enumerar una lista de los documentos primarios que son útiles para definir el problema de investigación, pues se tratan de ejemplares antiguos de una revista que hasta ahora habían pasado desapercibidos al historiador de las relaciones públicas. En nuestro caso, consideramos necesario comentar y fundamentar los resultados encontrados, ya que en la presentación de los mismos se encuentra la justificación de la selección bibliográfica final: es decir, no parece pertinente señalar cuáles son los ejemplares de interés sin explicar antes por qué lo son.

Finalmente, se lleva a cabo la redacción del artículo de revisión. Guirao-Goris, Olmedo y Ferrer (2009: 5) sostienen que uno de los objetivos de este tipo de artículos es el de proporcionar información amplia sobre un tema, así como mostrar las evidencias disponibles. Ramos, Ramos y Romero (2003) consideran que no existe una estructura preestablecida para los artículos de revisión, y que será suficiente con que éstos respondan a las necesidades de la investigación, de una manera clara y comprensible. No obstante, establecen que el desarrollo y discusión del tema es un apartado indispensable. Por lo tanto, gran parte de la riqueza de estas conclusiones vendrá de la mano de las explicaciones que previamente se puedan añadir a los resultados, y esto pasa por contextualizarlos debidamente.

Las conclusiones que han dado a lugar se focalizan en torno a la figura de tres grandes profesionales de la publicidad de nuestro país. Precisamente, estos publicitarios han dado muestras de ser grandes conocedores de la disciplina de las relaciones públicas, por lo que no resulta extraño descubrir que antes de que pusieran en práctica estos conocimientos, escribieron sobre ellos para la revista Arte Comercial.

\footnotetext{
3 «Campaña de relaciones públicas», «acción de propaganda», «campaña de propaganda», ««acción social», ««acción educativa», ««acción de prestigio», «campaña social», «campaña educativa», «campaña de prestigio», «propaganda social», «publicidad social», «publicidad colectiva», «campañas de servicio público», etc.
} 


\section{Arte Comercial: revista técnica de publicidad y organización}

La revista Arte Comercial comienza a editarse en abril de 1946 y sobrevive hasta 1952. Con una media de 6 números al año, la colección llega a alcanzar los 41 nú$\operatorname{meros}^{4}$. La publicación contó con la participación de reconocidos profesionales de la publicidad y el propio director de la publicación, Emeterio Ruiz Melendreras, que en numerosas ocasiones escribió para la revista bajo pseudónimo (Eguizábal, 2003). Los temas tratados en los artículos son abundantes y variados, aunque los textos fueran cortos y se redujeran a bosquejos o introducciones. En muchos casos, los artículos se plantean con vocación didáctica, ya que el objetivo era instruir al profesional, enseñándole nuevas técnicas y formas de proceder. La revista alude continuamente a la situación de la comunicación comercial en países como Inglaterra, Francia, Holanda y EEUU, con abundantes ejemplos de campañas exitosas. Se mira al exterior para sugerir lo que se debería hacer dentro de nuestro país.

Durante su año IV, la revista Arte Comercial dedica un artículo en exclusiva a conceptualizar las relaciones públicas. Hasta entonces, las referencias a las relaciones públicas han sido vagas pero no inexistentes, y se producen sobre todo al hablar de la situación estadounidense. Esta aproximación a la disciplina de las relaciones públicas se produce desde el punto de vista de la publicidad, puesto que para los profesionales españoles del momento las relaciones públicas eran una técnica publicitaria más y no una disciplina independiente, aunque los autores no niegan su capacidad para ser autónomas y hacen hincapié en sus diferencias frente a la publicidad tradicional.

Tras seis años de publicación, Arte Comercial finaliza su publicación, de una manera abrupta e inesperada. Mientras se mantiene en activo, la dirección opta por un discurso corporativo. En las editoriales, argumentan a favor de la necesidad de que el sector publicitario se organice en una Agrupación o Asociación de Agencias ${ }^{5}$, y se creen centros y escuelas especializadas ${ }^{6}$. La revista también apoya activamente la celebración de congresos ${ }^{7}$, conferencias $^{8}$ y ferias ${ }^{9}$, dedicándoles números monográficos. Y, ocasionalmente, realizan números especiales, centrados en algún sector empresarial de interés publicitario, como la perfumería ${ }^{10} \mathrm{o}$ los vinos y licores ${ }^{11}$.

Así mismo, la revista de Melendreras va a denunciar la mala situación y los problemas por los que atraviesa la profesión publicitaria en la España a finales de los

4 1946: 5 números; 1947: 7 números; 1948: 4 números; 1949: 6 números; 1950: 6 números; 1951: 7 números; 1952: 6 números.

5 Arte Comercial, Año I, 1946, Número 4, pp. 3.

6 Arte Comercial, Año II, 1947, Número 5, pp. 3.

7 Arte Comercial, Año IV, Número 18, pp. 3. Editorial sobre el III Congreso Nacional de Publicidad; Arte Comercial, Año V, Número 29, pp. 3. Sobre el Congreso Mundial de la Publicidad celebrado en Londres.

8 Arte Comercial, Año V, Número 32. Parte del número se centra en la Conferencia Internacional de Publicidad, celebrada en Londres.

9 Arte Comercial, Año III, Número 15. Monográfico dedicado a la XVI Feria Oficial e Internacional de Muestras de Barcelona; Arte Comercial, Año IV, Número 20. Monográfico desde IX Feria Oficial y Nacional de Muestras en Zaragoza.

${ }^{10}$ Arte Comercial, Año IV, Número 22.

${ }^{11}$ Arte Comercial, Año IV, Número 27 
años cuarenta, y, en general, se vale de la palabra escrita para llevar "a cabo una acción publicitaria a favor de la publicidad" (Pérez Ruiz, 2001: 223). La existencia de Arte Comercial resulta de capital importancia, ya que atestigua la situación de la comunicación en España años antes de la recuperación económica, y permite al historiador actual ahondar en los orígenes de la profesión publicitaria, así como de las relaciones públicas, por suerte.

\section{Primera conceptualización española de las public relations: las good relations o "buenas relaciones"}

Mediado el año de 1950, en el número 25 de la publicación, el publicista Jorge Garriga firma un artículo titulado "Las P. R." ${ }^{12}$. De las public relations destaca extrañado la falta de tratamiento previo de las mismas en el panorama publicitario español de finales de los años cuarenta. Según le consta al autor, sólo Pedro Prat Gaballí había abordado el tema de las relaciones públicas dentro del House Organ de Oeste, su agencia de publicidad. Fundada en julio de 1939 (Barjau, 1999: 98), esta agencia catalana no tarda en editar su propio órgano de información, repitiendo la grata experiencia que tuvieron con la revista privada de la agencia Fama, de la que Prat Gaballí había sido director (Quintas Froufe, 2011: 12).

Jorge Garriga alude a un artículo de 1948, publicado en la longeva revista Printer's Ink ${ }^{13}$, firmado por E. F. Thomas ${ }^{14}$, director de relaciones públicas de la agencia de publicidad Geyer, Newell \& Ganger (McDonough y Egolf, 2002: 672). E. F. Thomas aborda la importancia de las relaciones públicas, y explica que la función comercial de la técnica de las relaciones públicas es la de permitir al profesional interpretar la opinión frente a la Dirección del negocio, y viceversa.

Jorge Garriga (1950a: 12) explica que el origen estadounidense de las relaciones públicas se produce pasada la II Guerra Mundial, cuando se percibe un nuevo "problema publicitario", ya que algunos de los nuevos medios empleados no encajaban del todo dentro los cánones de la llamada "publicidad pura" (prensa, cine, radio, escaparates, carteles, etc.). Estos nuevos medios podían suponer el éxito de la estrategia publicitaria y agrupaban un sinfín de "pequeñeces" y "detalles".

Para Garriga Puig, las relaciones públicas son una nueva técnica publicitaria. La concepción de la disciplina de las relaciones públicas como herramienta publicitaria va a ser una constante en los primeros manuales de publicidad que tratan la materia en España durante los años cincuenta (Beneyto, 1957: 211; Prat, 1959: 205). No obstante, desde el primer momento, a las relaciones públicas se les asignan unos objetivos y finalidad diferentes a la publicidad, próximos a los ámbitos periodístico y propagandista (Reina y González, 2014b).

En el artículo, el autor también opta por dejar patente desde el primer momento los puntos en común que las relaciones públicas tienen con la publicidad, así como sus diferencias (Garriga, 1950a: 12):

\footnotetext{
12 Arte Comercial, "Las P.R.”. Año IV, Número 25, pp. 12-13.

${ }^{13}$ Editada en EEUU desde 1888, se trata de una voluminosa revista técnica sobre publicidad que lleva a alcanzar las 650 páginas en su versión semanal, y las 900 en los volúmenes mensuales. La publicación echa el cierre en 1972, una década después del fallecimiento del famoso publicista.

${ }^{14}$ Printer's Ink, 30 de Julio de 1948.
} 
Las P.R. pueden confundirse con la publicidad, en que aquéllas tienen como fin influir en la opinión; pero se distinguen de la publicidad en que el objeto, directo o indirecto, de ésta es hacer comprar, en tanto que las P.R. se proponen sólo crear alrededor de la firma una atmósfera favorable. Las dos técnicas -la publicidad y las P.R.- se sirven a menudo de los mismos medios para actuar sobre la masa; pero los empleados por las P.R. se alejan en lo posible de los usuales utilizados en publicidad, ya que generalmente éstas traducen su cometido de forma poco velada, y la tramoya de las P.R. debe ser perfectamente invisible.

Para reforzar estas diferencias, el autor del texto sitúa el nacimiento de las relaciones públicas norteamericanas en el ámbito político y periodístico, en las "conferencias de prensa" que el Ministerio de Información llevaba a cabo durante la II Guerra Mundial para explicar a los periodistas, en lenguaje corriente, "los textos publicados en el Boletín oficial, al objeto de hacer comprender y aceptar los artículos, a menudo oscuros, de un decreto-ley" (Garriga, 1950a: 12). De ahí surgen los P.R. Man, que desempeñan el papel de agentes de la opinión pública, forjados en el mundo del periodismo y la publicidad, como una nueva concepción de los propagandistas.

Finalmente, cabe destacar la sugerencia de traducción que Jorge Garriga propone para el término P.R. o public relations. Aunque no desdeña la idea de Prat Gaballí de traducirlas como "relaciones generales" (R.G.), prioriza el uso del término "buenas relaciones" (B.R.).

Apoyándose en un artículo firmado por Mr. Randall de $1949^{15}$, Jorge Garriga enumera siete argumentos a favor de la elección terminológica de "buenas relaciones" frente al polémico uso de la fórmula "relaciones públicas". A grandes rasgos, el autor viene a decir que (Garriga, 1950a: 13): la traducción de las public relations como "buenas relaciones" resultaría más exacta y fácil de comprender que "relaciones públicas"; designaría correctamente al objetivo de la práctica; implicaría un mayor nivel de buena fe; y sería más familiar, favorable y popular. Pero, a pesar de estos esfuerzos, la iniciativa de Jorge Garriga no llega a arraigar en la práctica profesional, que se decanta por el consabido término "relaciones públicas", ya que empezaba a ser el más utilizado y conocido (Prat, 1959: 453), convirtiendo la sugerencia de traducción de Jorge Garriga de las public relations como "buenas prácticas" en uno de tantos intentos fallidos.

En otro artículo, un número más tarde ${ }^{16}$, Jorge Garriga propone diferenciar entre publicidad y propaganda, ya que considera que la misión de esta última es la de influir sobre la masa. El autor, no obstante, opina que existen diferentes tipos de publicidad, así como hay diferentes clases de propaganda, entre la que incluye a la "propaganda económica privada"; es decir, a las public relations. Esta clasificación, ofrecida tan a bocajarro, es un tema que daría pie a otro debate, según explica el propio autor (Garriga, 1950b: 24).

Jorge Garriga continuará escribiendo de manera esporádica para la revista Arte Comercial $^{17}$, pero ni él, ni la publicación abordarán nuevamente el tema de las public

\footnotetext{
${ }^{15}$ Printer's Ink, 23 de Diciembre de 1949, "Public Relations or Good Relations?"

${ }^{16}$ Arte Comercial, "Terminología publicitaria". Año IV (1950), № 26, pp. 24.

${ }^{17}$ Arte Comercial, "El SOS de una marca". Año VI (1952), No 37, pp. 32-35.
} 
relations, dejando que sean otros profesionales del mundo de la publicidad los que retomen al tiempo, por otros cauces y medios, el trabajo de conceptualizar y traducir el término de las relaciones públicas en nuestro país.

\section{Pedro Prat Gaballí y las "relaciones generales"}

En diciembre de 1949, Pedro Prat Gaballí publica en la revista mensual argentina Ímpetu: revista de propaganda y ventas, su artículo "Una técnica naciente: $<<$ Las relaciones generales $>>18$. La revista Ímpetu nace en Buenos Aires en 1933, primera revista del país sobre la profesión publicitaria (Checa, 2007: 101). El artículo será escuetamente referenciado por la revista Arte Comercial $^{19}$, que deja constancia de su existencia.

En su artículo, Jorge Garriga alude a la definición de relaciones públicas hecha por Prat Gaballí en el house organ de su agencia de publicidad OESTE, a las que Prat Gaballí se refiere como "relaciones generales", en un intento por evitar que se confundan con las "relaciones oficiales", ya que cree que ambos términos son muy parecidos. Estas relaciones generales" se definirían, por tanto, como "el sistema para alcanzar la comprensión, cooperación y participación humana, dentro del estadio comercial, político, benéfico, religioso, etc.” (Garriga, 1950a: 12).

En cuanto a las obras de Prat Gaballí que pueden arrojar algo de luz a este estudio, cabe citar dos. No obstante, es necesario explicar que median tres décadas entre la publicación de la primera, "Publicidad Racional" (1934), y la segunda, "Publicidad Combativa" (1953). Este segundo título se había planeado como una revisión y puesta al día de la primera obra, para adecuarla a las nuevas ideas y tendencias en comunicación que se habían producido pasada la II Guerra Mundial, ya que además el libro de 1934 se encontraba agotado. Pero rápidamente Prat Gaballí cambia de opinión y se da cuenta de la necesidad de escribir algo nuevo y actual, dando como resultado un manual completamente diferente y con entidad propia. En esta nueva publicación de 1953, las relaciones públicas consiguen hacerse con un espacio propio entre los conocimientos sobre publicidad.

Nuevamente, Prat Gaballí traduce las relaciones públicas como "relaciones generales", pero cambia radicalmente su definición. Prat Gaballí, que había visitado los Estados Unidos en 1911 y hablaba inglés con fluidez (Rom, Altarriba y Martorell, 2009: 4), entiende que el término de las public relations comprende "las relaciones con el público, los organismos públicos o los individuos de la propia organización, que puede tener una empresa para cultivar su aprecio y simpatía" (Rodríguez Salcedo, 2010: 61) y las presenta de manera sucinta como "un fenómeno empleado para aprovechar toda clase de coyunturas que brindan las relaciones personales para convertirlas en fomento de simpatía y base de confianza y prestigio en relación con la empresa y sus productos" (Gutiérrez y Rodríguez, 2009: 16).

En la $2^{a}$ edición revisada de la obra, Prat Gaballí corrige algunos aspectos del texto, y modifica ligeramente la definición de "relaciones generales", donde reconoce que es más común referirse a las mismas como "relaciones públicas" (Prat, 1959: 453). Así mismo, se amplían significativamente el número de páginas, y el espacio

\footnotetext{
${ }_{18}$ Ímpetu: revista mensual de propaganda y ventas, Año XVII, Número 185.

${ }^{19}$ Arte Comercial, "Bibliografía". Año IV (1950), N 23, pp. 51.
} 
destinado a la conceptualización de las relaciones públicas: ya que a la explicación sobre el origen histórico de la disciplina, se le añade la situación norteamericana, y se dedica parte de un capítulo a hablar de las funciones y áreas de influencia de las relaciones públicas (Reina y González, 2014b: 183-186). Desgraciadamente, Pedro Prat Gaballí fallece en 1962, convirtiendo a ésta en su obra póstuma. Su papel como padre de la publicidad técnica española es inconmensurable, y entre sus logros dentro del ámbito de las relaciones públicas se encuentra, además, el haber redactado el prefacio del libro "Relaciones Públicas", de Nielander y Millar; traducido y publicado en España en 1958 (Montero, Rodríguez y Verdera, 2010: 195).

\section{Francisco García Ruescas: influencia y referencias a la profesión de las relaciones públicas en EEUU}

En octubre de 1946, Francisco García Ruescas viaja a Nueva York para conocer de primera mano el estado de la publicidad norteamericana. Durante tres meses, el publicista aprende sobre el sistema de trabajo del país, visita agencias, anunciantes y a sus homólogos publicitarios, y contacta con importantes firmas que planeaban su desembarco en España, un mercado virgen al que veían mucho potencial (García Ruescas, 1995: 94-98).

A su regreso, García Ruescas, como Director General de la agencia Alas, publica diversas noticias y artículos sobre su estancia en EEUU. Para la revista Arte Comercial, se compromete a escribir una serie de "artículos informativos", donde difunde los conocimientos que ha adquirido en su periplo, y compara la situación del mercado estadounidense con el español ${ }^{20}$. Al anunciar púbicamente su viaje, García Ruescas (1946: 5) explica el objeto que le mueve a escribir los textos:

En artículos sucesivos iré dando a conocer con amplios detalles cuales son los buenos servicios, basándome para ello en la experiencia de verdaderos técnicos publicitarios, la mayoría colegas de América que me honran con su consideración. Asimismo transmitiré a los lectores mis impresiones de las Empresas de los Estados Unidos y de su clientela una vez realice el viaje que me propongo para un futuro muy próximo.

Si ello sirve para orientación en España, ese será mi mejor premio, ya que así lograremos situarnos en el sitio que nos corresponde.

De esa serie de artículos sobre "La Publicidad en Norteamérica", hay que destacar dos en concreto, que versan sobre las agencias de publicidad estadounidenses. En el artículo de 1947, "Cómo sirve la Agencia de Publicidad a sus clientes"21, Francisco García Ruescas define el "servicio de agencia", la compensación económica de las agencias, las relaciones que mantienen éstas con los medios publicitarios, y las relaciones entre las agencias y sus clientes. Desde el punto de vista de las

\footnotetext{
${ }^{20}$ Arte Comercial, "desde Norteamérica”. Números 6, 7, 8, 9, 11 y 13.

${ }^{21}$ Arte Comercial, Año II, número 7, pp. 32-33.
} 
relaciones públicas, nos encontramos por primera vez con el término de las "relaciones públicas" traducido como tal dentro de la revista Arte Comercial, sin recurrir a una traducción alternativa. No obstante, y aunque se trata de una referencia corta y de pasada, nos permite comprobar que se trata de un término ya conocido por los profesionales de la publicidad en España, ya que a juicio del propio autor -y de la publicación-su inclusión dentro del texto no requiere de una explicación complementaria, como pudiera ser una anotación a pie de página o una descripción entre paréntesis.

Esta alusión a las relaciones públicas se produce cuando el autor describe los principales servicios que ofrecen las agencias de publicidad norteamericanas a finales de los años cuarenta. Estos servicios de agencia se centran en el estudio del producto o servicio; el análisis del mercado; en conocer los factores de distribución y venta; dominar los medios publicitarios más convenientes; formalizar y ejecutar el plan de comunicación publicitaria; y cooperar con el jefe de ventas del cliente. No obstante, Francisco García Ruescas considera que existen otros servicios adicionales en algunas agencias de publicidad, "tales como asesoramiento en la presentación de los productos, relaciones públicas, exhibiciones, etc. Estos servicios se efectúan, claro es, en estrecha relación con el cliente o con un experto que trabaja para él" (García Ruescas, 1947a: 32).

Unos números después, y en ese mismo año, Francisco García Ruescas vuelve a retomar el tema de las agencias de publicidad norteamericana dentro de la serie de artículos que está escribiendo para la revista Arte Comercial. En esta ocasión, la referencia a las relaciones públicas se torna algo más vaga, pero no por ello deja de ser importante para la historia de los orígenes de esta disciplina en nuestro país. En el artículo "Lo que es una Agencia de Publicidad"22, el autor reflexiona sobre el papel y misión de las agencias en la economía norteamericana, incidiendo en su número y estructura. Al explicar el funcionamiento de una agencia de publicidad estadounidense, el autor ofrece un panorama que casa perfectamente con la razón de ser de las relaciones públicas, ya que el papel de la agencia incluye "las relaciones con los públicos" del cliente (García Ruescas, 1947b: 39):

Las relaciones que existen entre el cliente y la agencia son tan estrechas y confidenciales, que tienen mucha semejanza con las que existen entre un abogado y su cliente. Esto es muy necesario, porque la agencia necesita estar muy familiarizada con todos los aspectos del negocio del cliente. Necesita conocer su historia, sus problemas, su pasado y presente y los planes que tiene para el futuro, ya que la agencia precisa apreciar en detalle toda la organización para poder aconsejar no sólo la manera de crear una buena publicidad, sino resolver problemas de fabricación, perfeccionamiento, presentación, relaciones con el público y, en fin, todos los problemas que tengan relación con el producto del cliente.

Como se puede comprobar al estudiar detenidamente estos dos artículos, el autor pasa de puntillas por el tema de las relaciones públicas dentro de la revista Arte Comercial, hasta casi convertir estas aportaciones en meras anécdotas. Sin embargo,

${ }^{22}$ Arte Comercial, Año II, número 11, pp. 38-39. 
no por ello se les debe restar importancia, ya que muy posiblemente tengan el honor de ser las primeras menciones que sobre las relaciones públicas se realizan en una publicación especializada en España.

Una vez que García Ruescas abandona Alas, funda su propia agencia en Abril de 1949, llamada Ruescas Publicidad. El publicista organiza una agencia moderna, emulando el ejemplo de las agencias de publicidad estadounidenses, con una estructura compleja y unos servicios diversificados, incluyendo actividades de relaciones públicas (García Ruescas, 1995: 102):

Se iniciaron los servicios de Relaciones Públicas con noticias e informaciones sobre las actividades de nuestros clientes. Editamos un Boletín mensual para información de nuestros clientes y al mismo tiempo como vehículo promocional. Es decir, ya éramos una agencia de SERVICIOS PLENOS.

Sobre la existencia de estos boletines mensuales tenemos clara constancia gracias a la revista Arte Comercial, y el boletín de pedido que en ella se anuncia. Para 1948, se planea la edición del primer Anuario GARÚ: Anuario Artístico y publicitario, "un lujoso volumen de cerca de 200 páginas y más de 100 grabados, muchos de ellos a color. Recopila los mejores dibujos publicitarios publicados en el año 1947. Índices de dibujantes, técnicos, directores, publicaciones, tarifas y agencias", con prólogo de Cecilio Barberán y al imponente precio de 200 pesetas de la época ${ }^{23}$.

Pocos meses después, se anuncia la Segunda edición del Anuario GARÚ, con la intención de ser publicado a principios de 1949, al mismo precio de 200 pesetas, pero aumentando el número de páginas hasta alcanzar las 300, ya que se pretende incluir algunas de las grandes campañas efectuadas en otros países, como Estados Unidos, Gran Bretaña, Francia, Holanda y Suiza. Así mismo, como principal novedad de la publicación se incluyen abundantes estadísticas sobre la publicidad española y extranjera, con amplios datos sobre las "Asociaciones técnicas" de cada país. Francisco García Ruescas se encarga de la dirección artística del Anuario, y del mismo se dice que "recopilará los mejores servicios técnicos presentados por la Industria y el Comercio, a través de las Empresas de Publicidad, durante el año actual"24.

Finalmente, en 1952 se anuncia el último y III Anuario de Publicidad GARÚ, en colaboración con la revista Arte Comercial, y del que se esperaba que figurara lo más destacado de la publicidad nacional y extranjera. El volumen de 250 páginas incluiría más de 900 ilustraciones, una "síntesis estadística del mercados español", y un sumario con la lista de los artículos que se planeaban publicar ${ }^{25}$.

El importante papel de Francisco García Ruescas en el terreno de las relaciones públicas españolas no se redujo a la edición de estos Anuarios. En Julio de 1953, su agencia Ruescas Publicidad lleva a cabo la inauguración del Hotel Castellana-Hilton en Madrid. Entre las actividades de relaciones públicas de la agencia estaba el atender a la prensa, el envío de comunicados de prensa y despertar el interés mediático. Un

\footnotetext{
${ }^{23}$ Arte Comercial, Año III, número 14, pp. 1.

${ }^{24}$ Arte Comercial, Año III, número 16, pp. 1.

25 Arte Comercial, Año VI, número 40, pp. 1.
} 
año después, se encargan de organizar una exposición de obras de arte procedentes de Canadá, patrocinada por la marca de whisky Seagram. A estas lista de actividades de relaciones públicas habría que sumar otras de menor envergadura, como el patrocinio de unos concursos hípicos para la marca de cigarrillos Camel, o los servicios de relaciones públicas que realizaron para la World Promotion Pictures en el festival de San Sebastián en 1959 (Reina y González, 2014a: 11-13).

\section{Conclusiones}

Desde el punto de vista de las relaciones públicas, la revista Arte Comercial resulta de enorme valor por ser presumiblemente la primera publicación española especializada que aborda el tema de las relaciones públicas.

A tenor de los resultados de la revisión bibliográfica, los números de la revista Arte Comercial que resultan de capital interés para este estudio se pueden agrupar dentro de dos áreas diferenciadas, según su grado de importancia y su capacidad para contribuir al mejor conocimiento teórico del origen de la disciplina de las relaciones públicas en nuestro país: artículos y menciones.

En cuanto a los artículos, se debe hacer especial hincapié en el texto publicado en el número 25 de la revista Arte Comercial, dedicado en exclusiva a las public relations, traducidas por el autor como "buenas relaciones". Este texto de 1950, firmado por el publicista Jorge Garriga, pone de manifiesto el interés que ya empiezan a despertar en España las relaciones públicas a principios de los años cincuenta, y la información que muestra es variada y rica en datos. El artículo identifica y explica el origen de las relaciones públicas en EEUU, una vez terminada la II Guerra Mundial; enumera una serie de interesantes ejemplos de campañas en el ámbito europeo; presenta las diferencias y similitudes existentes entre la publicidad y las relaciones públicas; y aporta algunas definiciones clave, con especial interés por la de Prat Gaballí; finalmente, desarrolla una serie de argumentos sobre cómo considera el autor que debería traducirse el término en España. También merece tenerse en cuenta el número 23 de la revista Arte Comercial, que alude a la difusión de otro artículo sobre las relaciones públicas en una publicación argentina de la mano del publicista catalán, Pedro Prat Gaballí, en este caso traducidas como "relaciones generales".

En según lugar, se encuentra una pequeña pero significativa lista de referencias teóricas sobre las relaciones públicas, posiblemente las primeras menciones se producen en España que sobre la materia. Estas referencias teóricas aluden tanto a las funciones y naturaleza de las relaciones públicas, como a su tipología y entorno de trabajo -números 7, 11 y 26-. Así mismo, hallamos abundantes alusiones a la salida al mercado de un boletín de información, académicamente considerado como un ejemplo patrio de actividad de las relaciones públicas a finales de los años cuarenta -números 14, 16 y 40-: el Anuario GARÚ. Todas estas referencias dentro de los artículos y anuncios giran en torno a la figura de Francisco García Ruescas, que es quien firma las propuestas, un destacado profesional español fuertemente influido por la publicidad estadounidense.

Estos resultados, aunque dispersos y escuetos, nos pueden ayudar a tener una visión panorámica más completa del estado de la disciplina de las relaciones públicas en España desde finales de los años cuarenta. Por un lado, al encontrarse la 
comunicación de las organizaciones en un estado embrionario o casi inexistente, es de recibo esperar que sean los publicistas, o las agencias de publicidad donde desempeñar sus servicios, los sujetos que lleven a cabo las primeras actividades de relaciones públicas dentro del país, aunque éstas se produzcan desde el ámbito de la comunicación comercial, con fines publicitarios; por otro lado, ya que la revista Arte Comercial es una de las pocas publicaciones especializadas en temas de comunicación sobre la que tenemos constancia, no debe sorprendernos que el modo en que se presenta a las relaciones públicas sea desde la perspectiva de la publicidad, ya que en aquellos momentos se las consideraba como una técnica publicitaria más. Dicho de otro modo, en esta etapa histórica, se piensa que las relaciones públicas deben formar parte de la disciplina publicitaria, como una herramienta menor de corta influencia.

El despegue de las relaciones públicas como una disciplina autónoma e independiente no se llegará a producir en España hasta la década de los sesenta, cuando se constituya la $S A E$ de $R P$, primera agencia de relaciones públicas del país, cuyas primeras actividades giraron en torno a la organización de eventos. Para entonces, ya operan en España algunos profesionales freelance de las relaciones públicas que ofrecen sus servicios, y se considera que a la profesión le aguarda un futuro prometedor y brillante.

Las futuras líneas de investigación pasan por encontrar nuevas fuentes primarias a las que someter a revisión y análisis. Para ello, es necesario presumir que las relaciones públicas existen en nuestro país desde antes del nacimiento oficial de la profesión, y llevar a cabo una labor de rastreo y localización de nuevos ejemplos, ya se traten de actividades de relaciones públicas aisladas que han pasado desapercibidas hasta ahora, artículos de divulgación publicados en revistas menores, o manifestaciones publicitarias mal identificadas. El trabajo del investigador empieza por cuestionar lo que tradicionalmente se ha dado por hecho.

\section{Referencias bibliográficas}

ALMANSA, Ana (2011). Del gabinete de prensa al gabinete de comunicación: la dirección de comunicación en la actualidad. Zamora: Comunicación Social y Publicaciones.

ARCEO, Antonio (1999a). Estrategias de Relaciones Públicas: Metodologías. Madrid: ICIE, Complutense de Madrid.

ARCEO VACAS, Antonio (2004a). La teoría de las Relaciones Públicas. En ARCEO VACAS, José Luis (Dir.). Las Relaciones Públicas en España. Madrid: McGraw-Hill, pp. 337-359.

ARCEO, José Luis (1999b). Tratado de Publicidad y Relaciones Públicas. Madrid: ICIE, Universidad Complutense de Madrid.

ARCEO, José Luis (2004b). Las relaciones públicas en España. Barcelona: McGraw-Hill. 
ARCEO, José Luis (2006). La investigación de relaciones públicas en España. $R e$ vista Análisi. Quaderns de Comunicació i Cultura, no 34, pp. 111-124.

ARMENDÁRIZ, Enrique (2012). Relaciones Públicas pioneras en España. Algunos precedentes en la primera mitad del siglo XX y pasos preliminares de la nueva profesión. Revista Análisi. Quaderns de Comunicació i Cultura, n 45, pp. 15-31.

BARJAU, Santi (1999). Els inicis del pensament publicitari: Pere Prat Gaballí, Rafael Bori i el Publi-Club. La teoria i la práctica de la publicitat <<racional >> a Catalunya entre 1915 i 1939. En: Boletín de la Societat Catalanya d'Estudis Histórics, $\mathrm{n}^{\circ} 10$, pp. 89-105.

BENEYTO, Juan (1957). Mass Communications. Un panorama de los Medios de Información en la Sociedad Moderna. Madrid: Instituto de Estudios Políticos.

BENEYTO, Juan (1961). Teoría y técnica de la opinión pública: cinco estudios sobre opinión, tiempo y sociedad. Madrid: Editorial Tecnos.

CASTILlO, Antonio (2009). Relaciones Públicas: teoría e historia. Barcelona: Editorial UOC.

CHECA, Antonio (2007). Historia de la Publicidad. Oleiros (La Coruña): Netbiblo. EGUIZÁBAL, Raúl (1998). Historia de la publicidad. Madrid: Eresma-Celeste.

EGUIZÁBAL, Raúl (2003). Emeterio R. Melendreras. Vidas de Anuncio”. En: Publifilia, $\mathrm{n}^{\mathrm{o}}$ 7. Disponible en: http://www.academiadelapublicidad.org/portfolio/ emeterio-r-melendreras-2/ [consultado en Octubre de 2015].

FONTCUBERTA, Joan (1998). Hora Cero: El ayer de la publicidad y las relaciones públicas. Barcelona: Thassalia.

GÁLVEZ, Alberto (2002). Revisión bibliográfica: usos y utilidades. En: Revista Matronas Profesión, $\mathrm{n}^{\mathrm{O}}$ 10, pp. 25-31.

GARCÍA RUESCAS, Francisco (1946). Porcentajes. En: Arte Comercial: Revista Técnica de Publicidad y Organización, Año I (1946), nº 4, pp. 5.

GARCÍA RUESCAS, Francisco (1947a). Cómo sirve la Agencia de Publicidad a sus clientes. En: Arte Comercial: Revista Técnica de Publicidad y Organización, Año II, número 7, pp. 32-33.

GARCÍA RUESCAS, Francisco (1947b). Lo que es una Agencia de Publicidad. En Arte Comercial: Revista Técnica de Publicidad y Organización, Año II, número 11, pp. 38-39.

GARCÍA RUESCAS, Francisco (1995). Relatos al Final del Camino. Madrid: Diamer.

GARRIGA, Jorge (1950a). Las P.R. Revista Arte Comercial: Revista Técnica de Publicidad y Organización, Año IV, N 25, pp. 12-13.

GARRIGA, Jorge (1950b). Terminología publicitaria. Revista Arte Comercial: Revista Técnica de Publicidad y Organización, Año IV (1950), No 26, pp. 24

GÓMEZ LUNA, Eduardo et. al. (2014). Metodología para la revisión bibliográfica y la gestión de temas científicos, a través de su estructuración y sistematización. En: Revista DYNA, n 81(184), Abril, pp. 158-163.

GUIRAO-GORIS, Josep Adolf; OLMEDO SALAS, Ángela; y FERRER FERRANDIS, Esperanza (2008). El artículo de revisión. En: Revista Iberoamericana de Enfermería Comunitaria, Año 1(1), nº 6, pp. 1-25.

GUTIÉRREZ, Elena y RODRÍGUEZ, Natalia (2009): “Cincuenta años de relaciones públicas en España. De la propaganda y la publicidad a través de la gestión de la reputación”. Revista Doxa Comunicación, nº 9, (9-33). 
HERNÁNDEZ, Roberto; FERNÁNDEZ, Carlos; y BAPTISTA, Pilar. (2010). Metodología de la investigación. Madrid: McGraw-Hill. 5ª Edición.

LÓPEZ CASTRO, Jesús (2005). Historia de las relaciones públicas en España. En BARQUERO CABRERO, José Daniel y BARQUERO CABRERO, María (coord.) Manual de Relaciones Públicas, Comunicación y Publicidad. Barcelona: Gestión 2000, pp. 517-562.

MCDONOUGH, John y EGOLF, Karen (2002). The Advertising Age Encyclopedia of Advertising. Volume 3. Londres: Routledge \& Ill edition.

MONTERO, Mercedes; RODRÍGUEZ, Natalia; y VERDERA, Francisco (2010). La edad de oro de la comunicación comercial. Historia de la publicidad y de las relaciones públicas en España (Volumen 1). Zamora: Comunicación Social Ediciones y Publicaciones.

NOGUERO I GRAU, Antonio (1995). Programación y técnicas de relaciones públicas. Barcelona: EUB.

PÉREZ RUIZ, Miguel Ángel (2001). La publicidad en España: anunciantes, agencias, centrales y medios. 1850-1950. Madrid: Editorial Fragua.

PRAT, Pedro (1934). Publicidad Racional. Barcelona: Editorial Labor.

PRAT, Pedro (1959). Publicidad Combativa. Barcelona: Editorial Labor. 2a Edición revisada.

QUINTAS, Eva (2011). El legado del hombre que se tomó la publicidad en serio: Pedro Prat Gaballí. Aproximación a sus contribuciones teóricas y profesionales. En: Área Abierta, n 30, pp. 1-18.

RAMOS, Miguel, H; RAMOS, Ma Florencia; y ROMERO, Enrique (2003). Cómo escribir un artículo de revisión. En: Revista de Postgrado de la Vía Cátedra de Medicina, no 126, Abril, pp. 1-3.

REINA, Jesús (2015). Antecedentes de relaciones públicas en la prensa malagueña de principios del siglo XX. Ámbitos: Revista Internacional de Comunicación, $\mathrm{n}^{\mathrm{o}}$ 27, pp. 51-60.

REINA, Jesús y GONZÁLEZ, María Inmaculada (2014a). Antecedentes de relaciones públicas en los manuales de publicidad. Algunos precedentes de actividad en España desde mediados del siglo XIX. En: Revista de Comunicación Vivat Academia, Año XVII, No 128, pp 1-20.

REINA, Jesús y GONZÁLEZ, María Inmaculada (2014b). Prat Gaballí y Juan Beneyto: una aproximación a la introducción de la disciplina de las relaciones públicas en España. En: Revista Internacional de Relaciones Públicas, Volumen IV, $\mathrm{n}^{\mathrm{0}} 7$, pp. 177-196.

RÍOS, Sonia (2004). La Crítica sobre diseño gráfico español en las revistas de arte comercial y publicidad (1900-1970). Tesis doctoral. Departamento de Historia del Arte. Universidad de Málaga. Málaga.

RODRÍGUEZ SALCEDO, Natalia (2007). La historia como tendencia actual de las relaciones públicas. Ponencia presentada en el Congreso Tendencias actuales de las Relaciones Públicas de la Asociación de Investigadores en Relaciones Públicas (AIRP).

RODRÍGUEZ SALCEDO, Natalia (2010). Relaciones Públicas en Dictadura: el inicio de la profesión en España (1960-1975). En MONTERO DÍAZ, Mercedes (coord.). La edad de oro de la comunicación comercial. Historia de la publicidad y de las relaciones públicas en España (Volumen 2). Zamora: Comunicación Social Ediciones y Publicaciones, pp. 61-105. 
ROM, Josep; ALTARRIBA, Miquel; y MARTORELL, Cristina (2009). El legado de Pedro Prat Gaballí: las raíces de la publicidad moderna. X Congreso de la Asociación de Historiadores de la Comunicación. Ponencia de la Mesa 1: Sociedad de Masas y Sociedad Industrial. Disponible en: https://www.academia.edu/6875403/ El_legado_de_Pedro_Prat_Gaball\%C3\%AD_las_ra\%C3\%ADces_de_la_publicidad_moderna [Consultado en Octubre de 2015].

SELLTIZ, CLAIRE; WRIGHTSMAN, Lawrence, S.; y COOK, Stuart, W. (1980). Métodos de investigación en las relaciones sociales. Madrid: Rialp.

XIFRA, Jordi (2010). Relaciones Públicas, empresa y sociedad. Barcelona: Editorial UOC. 